\title{
MANAJEMEN PERAWATAN MESIN IQF MENGGUNAKAN METODE RELIABILITY CENTERED MAINTENANCE (RCM) STUDI KASUS DI PT ANEKA GAS INDUSTRI Tbk.
}

\author{
Puput Ansory \\ Teknik Industri, Fakultas Teknik \\ Universitas Maarif Hasyim Latif, Sidoarjo, Indonesia \\ e-mail : puputansory@gmail.com
}

\begin{abstract}
ABSTRAK
Penelitian ini dilakukan pada salah satu industri di kota Sidoarjo yang bergerak dibidang produksi udang beku. Seiring meningkatnya kapasitas produksi, performasi mesin pun kian lama semakin menurun akibatnya sering terjadi breakdown maintenance yang menyebabkan proses produksi terhenti dan banyak menimbulkan kerugian. Salah satu faktor didalamnya adalah tidak adanya manajemen perawatan yang diterapkan. Untuk mendapatkan hasil yang sesuai maka digunakanlah salah satu metode penelitian pada bidang perawatan, yaitu Reliability Centered Maintenance (RCM). Dengan metode tersebut, didapatkan penentuan mesin kritis, komponen mesin kritis, Failure Mode Effect Analysis (FMEA), perhitungan biaya kerugian, besarnya biaya perawatan, hingga penentuan interval perawatan yang optimal. Sehingga dari manajemen perawatan tersebut perusahaan dapat menghemat biaya hingga lebih dari Rp.404.956.008.00; biaya tersebut jauh lebih efisien daripada biaya breakdown maintenance yang selama ini dijalankan.
\end{abstract}

Kata kunci: FMEA, failure mode and effect analysis, Mesin IQF, Individual Quick Frezing, RCM, Reliability centered maintenance,

\section{PENDAHULUAN}

PT. Aneka Gas Industri Tbk. adalah sebuah perusahaan yang menyediakan produksi berbagai macam gas industri, terletak di Jl. Raya Surabaya Mojokerto Km. 19 Sidoarjo. PT. Aneka Gas Industri Tbk (PT. AGI) memproduksi bermacam jenis gas seperti Argon, Oksigen,

Nitrogen dsb. Perusahaan ini memiliki 252 filling station dan 28 plant yang tersebar diseluruh indonesia. Disamping memproduksi dalam bentuk gas, adapula yang di produksi dalam bentuk liquid, varian ini diperuntukkan bagi customer di bidang industri maupun medis yang membutuhkan konsumsi dalam jumlah besar, dimana produk berupa gas dikemas dalam (Dhamayanti, Alhilman, \& Athari, 2016)bentuk tabung (botol) sedangkan produk liquid ini didistribusikan dengan sebuah Cryogenic tank. Penjualan produk liquid kepada customer dikemas dalam tangki dan ditawarkan dengan sistem sewa ataupun pembelian tangki.

(Prasetya \& Ardhyani, 2019) Disamping menjual produk gas dan liquid, PT. Aneka Gas Industri Tbk. juga menyediakan layanan rental mesin pendingin untuk produk makanan yang disebut mesin IQF (Individual Quick Frozen) atau freezing tunnel untuk customer industri dibidang makanan beku (Frozen). Dimana pihak perusahaan (PT. AGI) selaku supplier memegang tanggung jawab penuh atas segala perawatan dan perbaikan pada mesin tersebut khususnya menjadi tanggung jawab bagian Customer Service Maintenance
PT Sekar Bumi, adalah salah satu customer PT. AGI yang bergerak dibidang produksi udang beku (Frozen shrimp), yang menggunakan layanan sewa mesin IQF dan cryogenic tank nitrogen dari PT AGI, perusahaan ini pula yang menjadi objek penelitian karena mesin IQF di perusahaan ini mengalami kerusakan dengan frekuensi dan kerugian paling besar dari tujuh customeryang ada.

\section{METODE PENELITIAN}

Metodologi penelitian merupakan langkahlangkah yang akan dilakukan dalam penelitian untuk mencapai tujuan yang diinginkan. Dalam penelitian ini digunakanlah metode perawatan bernama Reliability Centered Maintenance (RCM). Di dalam RCM sendiri terdapat tujuh tahapan yang harus didikerjakan berurutan yaitu meliputi:

1. Penentuan sistem dan Pengumpulan Informasi

2. Batasan Sistem

3. Deskripsi Sistem dan Functional Block Diagram

4. Penentuan Fungsi Sistem dan Kegagalan Fungsional

5. Failure Mode and Effect Analysis (FMEA)

6. Logic Tree Analysis (LTA)

7. Task Selection

Pada tahapan ini pengumpulan data dilakukan dengan beberapa cara antara lain:

1. Observasi lapangan 
Pengumpulan data dengan cara langsung terjun ke lapangan dengan mengamati jalannya proses produksi dan wawancara dengan operator mesin, kepala produksi maupun tim teknisi.

2. Kartu Gudang, Breakdown Report

Yaitu pengumpulan data dengan cara melihat laporan perbaikan yang selama ini berjalan serta menganalisa bagian bagian komponen mesin yang kritis.

\section{HASIL DAN PEMBAHASAN}

Berdasarkan data yang dihimpun dari wawancara dengan bagian produksi PT. Sekar Bumi, maka didapat hasil mengenai rata rata kerusakan mesin pada proses produksi dalam kurun waktu tiga tahun, adalah sebagai berikut:

Tabel 1 Frekuensi Breakdown Mesin Produksi mulai Januari 2015 - Desember 2018

\begin{tabular}{|c|c|c|c|c|c|c|}
\hline \multirow{2}{*}{ Tahun } & \multicolumn{6}{|c|}{ Breakdown Mesin } \\
\cline { 2 - 7 } & $\begin{array}{c}\text { Mesin } \\
\text { Sizing }\end{array}$ & $\begin{array}{c}\text { Mesin } \\
\text { IQF }\end{array}$ & $\begin{array}{c}\text { Mesin } \\
\text { Timbangan }\end{array}$ & $\begin{array}{c}\text { Storage } \\
\text { Tank } \\
\text { N2 }\end{array}$ & $\begin{array}{c}\text { Mesin } \\
\text { Packing }\end{array}$ & $\begin{array}{c}\text { Cold } \\
\text { Storage }\end{array}$ \\
\hline 2015 & 2 & 5 & 2 & 0 & 2 & 2 \\
\hline 2016 & 5 & 13 & 0 & 1 & 1 & 3 \\
\hline 2017 & 3 & 11 & 7 & 2 & 3 & 0 \\
\hline 2018 & 1 & 7 & 3 & 0 & 2 & 1 \\
\hline Total & $\mathbf{1 1}$ & $\mathbf{3 6}$ & $\mathbf{1 2}$ & $\mathbf{3}$ & $\mathbf{8}$ & $\mathbf{6}$ \\
\hline
\end{tabular}

Berdasarkan data diatas, maka diperoleh digram pareto untuk melihat komponen kritis dari yang terendah hingga tertinggi.

Frekuensi Kerusakan Mesin Lini Produksi

- Frekuensi Breakdown

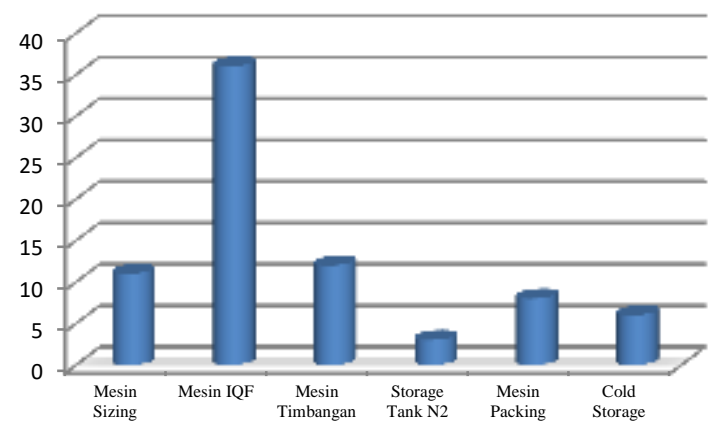

Gambar 1 Frekuensi Breakdown mesin produksi

Tabel 2 Frekuensi Breakdown mesin

\begin{tabular}{|l|c|c|c|c|}
\hline Mesin & $\begin{array}{c}\text { Jumlah } \\
\text { Breakdown }\end{array}$ & Kumulatif & Prosentase & $\begin{array}{c}\text { Prosentae } \\
\text { Kumulatif }\end{array}$ \\
\hline Mesin Sizing & $\mathbf{1 1}$ & 11 & $14 \%$ & $14 \%$ \\
\hline Mesin IQF & $\mathbf{3 6}$ & 47 & $47 \%$ & $62 \%$ \\
\hline $\begin{array}{l}\text { Mesin } \\
\text { Timbangan }\end{array}$ & $\mathbf{1 2}$ & 59 & $16 \%$ & $78 \%$ \\
\hline $\begin{array}{l}\text { Storage Tank } \\
\text { N2 }\end{array}$ & $\mathbf{3}$ & 62 & $4 \%$ & $82 \%$ \\
\hline Mesin Packing & $\mathbf{8}$ & 70 & $11 \%$ & $92 \%$ \\
\hline Cold Storage & $\mathbf{6}$ & 76 & $8 \%$ & $100 \%$ \\
\hline Total & 76 & \multicolumn{5}{|l}{} \\
\cline { 1 - 4 }
\end{tabular}

Dari hasil data di atas, maka dapat digambarkan pareto breakdown mesin produksi yaitu sebagai berikut:

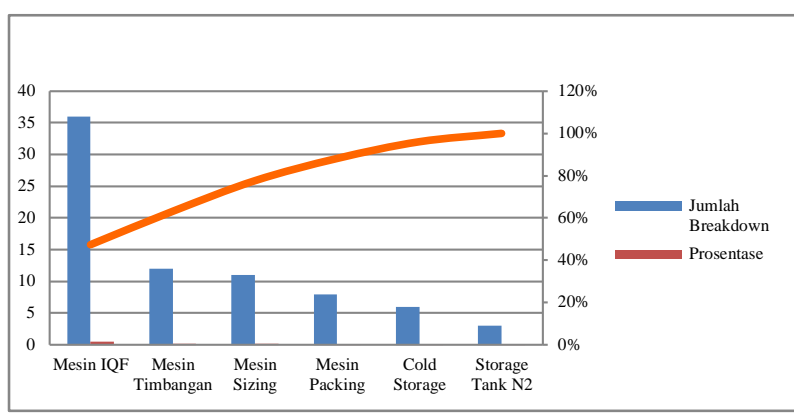

Gambar 2 Diagram Pareto Breakdown Mesin

\section{Definisi Batasan Sistem}

Adalah tahapan yang menjelaskan batasan batasan sistem dalam suatu proses yang akan diteliti

\section{Deskripsi Sistem}

1. Elektrikal

Merupakan gabungan dari beberapa perangkat elektrik sebagai sumber utama power supply dan komponen pengontrol seperti kontaktor, thermo control, inverter, MCB, push button, lampu indikator, dsb. Melalui panel elektrikal ini user melakukan perintah untuk menyalakan dan mematikan mesin IQF, mengatur kecepatan conveyor, memonitoring suhu dsb. Subsistem ini dilengkapi dengan over load, dimana pada keadaan tertentu saat mesin kelebihan beban akan mati secara otomatis agar tidak berimbas pada komponen lainnya (short).

2. Mekanikal

Motor gear dialiri daya 3 phase dan terjadi gerak putar, putaran motor dihubungkan dengan sprocket dari as motor menuju sprocket as utama belt conveyor setelah berjalan barulah dilakukan proses pendinginan flushing instalasi yaitu mengalirkan gas nitrogen bertekanan tinggi dengan tujuan untuk membersihkan pipa, selanjutnya dilakukan (pre cooling) yaitu mengalirkan cairan nitrogen dari tangki kriogenik melalui pipa $V G$ Line menuju injector assembly dan contol valve, dari control valve, cairan nitrogen disemprotkan ke wiremesh conveyor melalui nozzle yang tersebar didalam Box conveyor, pada pembacaan suhu dengan thermo couple yang terpasang pada body atas mesin ditransmisikan ke thermo control untuk mengirimkan pembacaan suhu pada panel elektrikal, hingga mencapai suhu yang di 
inginkan antara $-90^{\circ} \mathrm{s} / \mathrm{d}-100^{\circ} \mathrm{C}$. Setelah suhu tercapai, barulah udang yang sudah diproses kupas dan potong dimasukan melalui inlet assembly feeder dan berjalan melalui belt conveyor beku menuju outlet assembly. Setelah selesai barulah udang di timbang dan di packing untuk selanjutnya disimpan pada cold storage.

\section{Fungtional Block Diagram}

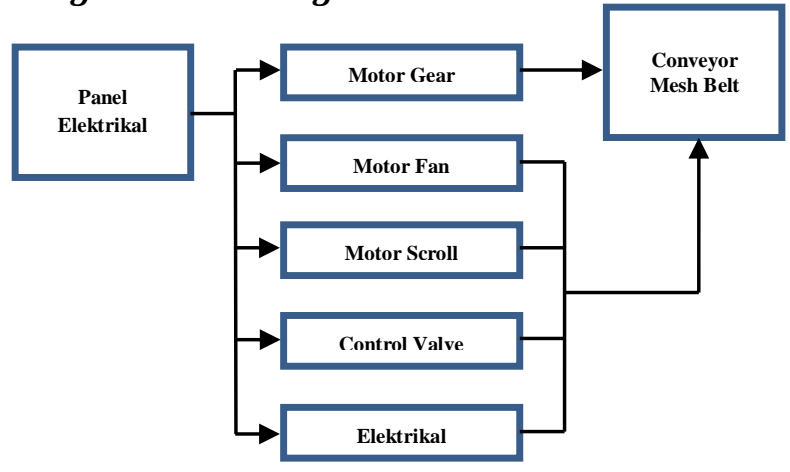

Gambar 3 Fungtional Block Diagram

Suatu sistem dapat di deskripsikan dengan berdasarkan fungsi dari subsistemnya, fungsi dari mesin IQF adalah untuk membekukan produk melalui belt conveyor box yang di dalamnya di spray dengan cairan nitrogen. Power dan control utama mesin IQF terdapat pada panel elektrikal, dimana hampir semua instrumen kendali utamanya menggunakan rangkaian elektrik di dalam panel, panel tersebut mengatur dan menjalakan motor gear conveyor yang merubah energi listrik menjadi energi mekanik untuk menjalankan conveyor meshbelt, disamping itu komponen pendukung lainya juga dijalankan guna mendukung jalannya mesin IQF untuk membekukan produk, seperti motor fan, motor scroll, Control valve, dan intrumen elektrikal lainya

\section{FMEA}

Failure Mode and Effect Analysis (FMEA) adalah proses mengidentifikasi kegagalan dari suatu komponen yang dapat menyebabkan kegagalan fungsi dari sistem (Azis, Suprawhardana, \& Purwanto, 2010).

Analisis pada tabel failure mode and effect analisys (FMEA) terdiri dari:

1. Function berfungsi untuk mendeskripsikan fungsi komponen yang dianalisis.

2. Functional failure berfungsi untuk menentukan kegagalan yang terjadi pada komponen.

3. Failure modes berfungsi untuk mengidentifikasi penyebab kegagalan yang terjadi pada komponen yang sedang dianalisis.

4. Failure effect berfungsi untuk mengidentifikasi dampak yang ditimbulkan oleh kegagalan fungsi komponen.

5. Saverity digunakan untuk menentukan rating dari dampak yang ditimbulkan oleh kegagalan fungsi komponen yang dianalisis.
6. Occurrence digunakan untuk menentukan rating frekuensi kerusakan komponen yang sedang dianalisis.

7. Detection digunakan untuk menentukan rating kemungkinan sebuah komponen dapat dideteksi terjadi kegagalan fungsi.

8. Risk priority number digunakan untuk menentukan angka prioritas resiko kegagalan fungsi yang didapatkan dari perkalian severity, occurrence, dan detection.

Hasil perhitungan RPN sendiri didapat dari perkalian Severity, Occurrence dan Detection. Setelah mendapatkan rangking perhitungan RPN, selanjutnya ditentukan prioritas mode kegagalan menggunakan metode $\mathrm{ABC}$ untuk dilakukan perbaikan. berikut ini hasil rekap RPN dari analisis FMEA.

Dari metode ABC didapatkan 4 komponen grade A dengan presentase kumulatif sebesar $40 \%$ yang dianggap sebagai komponen kritis dari keseluruhan total jumlah RPN komponen mesin. Komponenkomponen tersebut akan dilakukan analisa lebih mendalam. Adapun empat komponen tersebut antara lain:

\section{Gear Box Lifter \\ 2.Sprocket Penggerak \\ 3.Scraper \\ 4.Wiremesh Belt Conveyor}

Data kerusakan berupa tanggal dan jam terjadi kerusakan dan perbaikan berupa waktu downtime digunakan untuk menentukan parameter distribusi waktu time to repair (TTR) dan time to failure (TTF). Perhitungan time to repair memperhitungkan jumlah waktu ketika komponen rusak hingga komponen selesai diperbaiki. Perhitungan time to failure memperhitungakan jumlah waktu ketika komponen selesai diperbaiki hingga komponen rusak kembali.

Tabel 3. MTTR komponen GearBox Lifter

\begin{tabular}{|c|c|c|c|c|c|c|}
\hline \multirow{2}{*}{ No } & \multirow{2}{*}{ Tanggal } & \multicolumn{2}{|c|}{ Waktu Kerusakan } & Downtime & TTR & TTF \\
\cline { 3 - 7 } & & Mulai & Selesai & Menit & Jam & Jam \\
\hline 1 & 6-Jan & 14.00 & 22.00 & 480 & 8.00 & 0 \\
\hline 2 & 27-Jan & 9.00 & 18.00 & 540 & 9.00 & 467 \\
\hline 3 & 13-Feb & 10.00 & 13.00 & 180 & 3.00 & 376 \\
\hline 4 & 26-Mar & 13.00 & 15.00 & 120 & 2.00 & 960 \\
\hline 5 & 10-May & 8.00 & 10.30 & 150 & 2.30 & 1049 \\
\hline 6 & 21-Jun & 21.00 & 23.00 & 120 & 2.00 & 970,5 \\
\hline 7 & 25-Aug & 9.00 & 13.00 & 240 & 4.00 & 1522 \\
\hline 8 & 15-Sep & 8.00 & 11.30 & 210 & 3.30 & 475 \\
\hline 9 & 13-Oct & 14.00 & 18.00 & 240 & 4.00 & 626,5 \\
\hline 10 & 19-Nov & 6.00 & 9.00 & 180 & 3.00 & 852 \\
\hline 11 & 9-Dec & 10.30 & 15.30 & 300 & 5.00 & 433,5 \\
\hline
\end{tabular}


Tabel 4. MTTR komponen Sprocket

\begin{tabular}{|c|c|c|c|c|c|c|}
\hline \multirow{2}{*}{ No } & \multirow{2}{*}{ Tanggal } & \multicolumn{2}{|c|}{ Waktu Kerusakan } & Downtime & TTR & TTF \\
\cline { 3 - 7 } & & Mulai & Selesai & Menit & Jam & Jam \\
\hline 1 & 2-Feb & 18.00 & 22.00 & 240 & 4.00 & 0 \\
\hline 2 & 6-Mar & 9.00 & 16.30 & 120 & 7.30 & 750 \\
\hline 3 & 1-Jun & 15.00 & 20.30 & 330 & 5.30 & 2125 \\
\hline 4 & 9-Jul & 10.30 & 13.00 & 150 & 2.30 & 900 \\
\hline 5 & 12-Aug & 6.00 & 10.30 & 270 & 4.30 & 800 \\
\hline 6 & 21-Sep & 13.00 & 18.00 & 300 & 5.00 & 950 \\
\hline 7 & 10-Nov & 11.30 & 14.00 & 150 & 2.30 & 1200 \\
\hline 8 & 19-Dec & 9.00 & 13.00 & 240 & 4.00 & 925 \\
\hline
\end{tabular}

Tabel 5. MTTR komponen Scraper

\begin{tabular}{|c|c|c|c|c|c|c|}
\hline \multirow{2}{*}{ No } & \multirow{2}{*}{ Tanggal } & \multicolumn{2}{|c|}{ Waktu Kerusakan } & Downtime & TTR & TTF \\
\cline { 3 - 7 } & & Mulai & Selesai & Menit & Jam & Jam \\
\hline 1 & 9-Jan & 21.00 & 23.00 & 0.00 & 2.00 & 0 \\
\hline 2 & 15-Feb & 7.00 & 12.00 & 300 & 5.00 & 848 \\
\hline 3 & 9-Mar & 10.00 & 12.30 & 180 & 2.30 & 502 \\
\hline 4 & 13-May & 11.00 & 17.00 & 210 & 6.00 & 1534,5 \\
\hline 5 & 9-Jun & 16.00 & 20.00 & 240 & 4.00 & 623 \\
\hline 6 & 22-Aug & 14.00 & 19.30 & 330 & 5.30 & 1746 \\
\hline 7 & 19-Sep & 18.00 & 22.00 & 240 & 4.00 & 646,5 \\
\hline 8 & 5-Oct & 8.30 & 11.30 & 180 & 3.00 & 346,5 \\
\hline 9 & 8-Nov & 14.00 & 20.00 & 360 & 6.00 & 770,5 \\
\hline 10 & 29-Nov & 6.00 & 9.00 & 180 & 3.00 & 466 \\
\hline 11 & 24-Dec & 10.30 & 15.30 & 300 & 5.00 & 553,5 \\
\hline
\end{tabular}

Tabel 6. MTTR komponen Wiremesh Belt

\begin{tabular}{|c|c|c|c|c|c|c|}
\hline \multirow{2}{*}{ No } & \multirow{2}{*}{ Tanggal } & \multicolumn{2}{|c|}{ Waktu Kerusakan } & Downtime & TTR & TTF \\
\cline { 3 - 7 } & & Mulai & Selesai & Menit & Jam & Jam \\
\hline 1 & 21-Jan & 7.00 & 22.30 & 930 & 15.30 & 0 \\
\hline 2 & 13-Feb & 10.00 & 15.00 & 300 & 5.00 & 512 \\
\hline 3 & 16-Apr & 13.00 & 21.00 & 480 & 8.00 & 1462 \\
\hline 4 & 16-May & 18.00 & 23.30 & 330 & 5.30 & 694,5 \\
\hline 5 & 21-Jun & 9.30 & 16.30 & 420 & 7.00 & 839 \\
\hline 6 & 9-Aug & 9.00 & 19.30 & 630 & 10.30 & 1146 \\
\hline 7 & 5-Sep & 12.00 & 22.00 & 600 & 10.00 & 622,5 \\
\hline 8 & 29-Sep & 9.30 & 11.30 & 120 & 2.00 & 538,5 \\
\hline 9 & 29-Nov & 6.00 & 15.00 & 540 & 9.00 & 1418,5 \\
\hline
\end{tabular}

\section{Biaya Biaya yang Terlibat}

Biaya biaya yang dianalisa dalam hal ini adalah biaya biaya yang timbul akibat perawatan, biaya biaya yang timbul akibat kerusakan, biaya biaya yang berhubungan dengan adanya program persediaan.

Biaya perawatan terdiri dari biaya tenaga kerja perawatan. Sedangkan biaya kerusakan terdiri dari biaya kehilangan keuntungan akibat dari kerusakan mesin dan biaya tenaga kerja perbaikan

\section{Biaya Tenaga Kerja (C1)}

Asumsi biaya tenaga kerja untuk perawatan dan perbaikan adalah sama, sebab perbaikan maupun perawatan akan dilakukan oleh tim karyawan perusahaan penyedia mesin IQF (PT Aneka Gas Industri Tbk) dengan golongan yang sama. Dalam hal ini proses perawatan dilakukan oleh 2 orang sedangkan untuk perbaikan dilakukan oleh 4 orang.

Biaya seorang tenaga kerja dalam sebulan dengan gaji pokok (UMR) Rp. 3.864.000; yang menurut peraturan SDM, nilai gaji pokok dibagi 173. Maka dalam satu jam-nya untuk tenaga kerja reguler adalah sebesar = Rp. 3.864.000,- / 173

$=$ Rp. 22.335,- per jam

a. Jadi jika 4 orang orang melakukan perbaikan maka biayanya sebesar :

C1a = Rp. 22.335,- x 4 orang

$=$ Rp. 89.341,- $/$ jam

b. Jika 2 orang melakukan perawatan maka biayanya sebesar:

C1b = Rp. 22.335,- $\mathrm{x} 2$ orang

$=$ Rp. 44.670-, $/$ jam

\section{Biaya Kerugian Produksi (C2)}

Biaya kerugian produksi diperoleh dari keuntungan yang hilang akibat kerusakan/perawatan mesin yang mengakibatkan mesin berhenti beroperasi. Mesin IQF dengan kapasitas $1000 \mathrm{Kg} / \mathrm{jam}$ rata rata perhari (3 shift) memproduksi 24 Ton udang. Sedangkan harga udang beku /pack @ 2 lbs (908 gr) Rp. 95.000,-

$\mathrm{C} 2 \mathrm{a}$

$$
\begin{aligned}
& =\left(\frac{\text { Kapasitas Produksi }}{\text { Nettorpack }}\right)_{\text {harga pack }} \\
& =(1000 / 0,908) \text { Rp. } 95.000,- \\
& =1101 \text { x Rp. } 95.000,- \\
& =\text { Rp. } 104.625 .551,-/ \text { jam }
\end{aligned}
$$

Sedangkan dari PT. AGI mengalami hilangnya keuntungan (opportunity cost) penjualan liquid nitrogen akibat mesin IQF berhenti produksi, perhitungan per jamnya adalah:

Harga jual liquid nitrogen perkilogram Rp. 1.100,-

Sedangkan ratio mesin adalah 1:1,5 yakni $1 \mathrm{Kg}$ liquid nitrogen dapat membekukan 1,5 Kg udang. Sehingga didapat perhitungan:

$\mathrm{C} 2 \mathrm{~b}=$ (ratio $\mathrm{x}$ kapasitas produksi perjam) $\mathrm{x}$ harga liquid $/ \mathrm{kg}$

$$
\begin{aligned}
& =(1: 1,5 \times 1101) \times R p .1 .100,- \\
& =(0,667 \times 1101) \times \text { Rp.1.100,- } \\
& =734 \times \text { Rp.1.100,- } \\
& =\text { Rp. 807.400,- } / \mathrm{jam}
\end{aligned}
$$




\section{Biaya akibat Kerusakan (Cf)}

Jika mesin berhenti beroperasi akibat kerusakan diluar perkiraan, maka dapat menimbulkan biaya kerusakan. Biaya biaya kehilangan pendapatan akibat kerusakan dan biaya man power untuk perbaikan.

$\mathrm{Cf}=$ (Biaya man power + biaya kehilangan keuntungan akibat kerusakan) $\mathrm{x}$ rata rata waktu perbaikan + (biaya pengadaan spare part $\mathrm{x}$ banyaknya spare part)

$\mathrm{Cf}=(\mathrm{C} 1 \mathrm{a}+\mathrm{C} 2 \mathrm{a}+\mathrm{C} 2 \mathrm{~b}) \times$ MTTR + (biaya pengadaan spare part $\mathrm{x}$ banyaknya spare part)

$\mathrm{Cf}=$ Rp. 89.341,- + Rp. 104.625.551,- + Rp. 807.400,- x MTTR + (biaya pengadaan spare part $\mathrm{x}$ banyaknya)

\section{Biaya Perawatan (CM)}

Biaya untuk perawatan adalah biaya yang timbul karena adanya perawatan. Biaya untuk perawatan meliputi biaya tenaga kerja, biaya downtime (biaya downtime ditetapkan oleh perusahaan sebesar $5 \%$ dari biaya kerugian produksi) dan biaya spare parts. Biaya perawatan dihitung dengan rumus sebagai berikut:

\section{$\mathrm{CM}=$ Biaya tenaga kerja $\times$ MTTR + biaya material}

menunjukan bahwa perawatan Wiremesh Belt memiliki biaya tertinggi dengan jumlah Rp. 5.140.321,- karena komponen memiliki harga yang cukup mahal dengan nilai MTTR tertinggi sebesar 8,73788. Sedangkan Sprocket memiliki nilai MTTR terendah sebesar 4,36467 dan harga yang cukup murah sehingga memakan biaya perawatan terendah yaitu sebesar Rp. 1.569.970,-

\section{Biaya Perbaikan Karena Kerusakan Setiap Siklus} Perawatan (Cf)

Biaya perbaikan akibat kerusakan komponen setiap siklus perawatan adalah biaya yang timbul akibat adanya kerusakan komponen. Biaya ini meliputi biaya kerugian produksi, biaya tenaga kerja dan biaya material. Perbaikan Scraper memiliki nilai MTTR terendah sebesar 4,36467 dan harga yang cukup murah,

sehingga memakan biaya perawatan terendah sebesar Rp.457.045.943,-. Wiremesh Belt memiliki biaya tertinggi yaitu sebesar Rp. 914.986.152,- karena komponen ini memiliki harga yang cukup mahal dengan nilai MTTR tinggi sebesar 8,73788.

\section{Interval Perawatan Optimal}

Perhitungan interval perawatan optimal menggunakan rumus:

$\mathrm{TM}=\theta\left(\frac{C m}{(C f-C m)} \cdot \frac{1}{(\beta-1)}\right)^{\frac{1}{\beta}}$

Perhitungan untuk komponen gearbox lifter adalah sebagai berikut:

TM

$$
\text { 876. } 02\left(\frac{6.937 .872}{(137.700 .082-6.937 .872)} \cdot \frac{1}{(2,41018-1)}\right)^{\frac{1}{2,41018}}
$$

$\mathrm{TM}=224,628665$ komponen wiremesh belt memiliki interval perawatan paling lama dengan 236,0967 jam atau 10 hari, dan komponen Scraper dengan interval perawatan paling rendah dengan 80,497386 jam atau 3 hari.

\section{Total Cost (TC)}

Biaya sebelum adanya perawatan terencana (TP).

Berikut adalah perhitungan total biaya perawatan untuk koponen Gear Box Lifter, yaitu:

Dimana, Banyaknya kerusakan

$=\mathrm{N}=\frac{t}{M T T F}=\frac{2756}{4,41759}=623,869$

Total biaya sebelum adanya perawatan

= Biaya Kerusakan x Banyaknya Kerusakan

$=$ Rp. $462.587 .455 \times 623$

$=$ Rp. 288.191 .984 .465

Preventive Cost merupakan biaya yang timbul karena adanya perawatan mesin yang memang sudah dijadwalkan. Sedangkan Failure Cost merupakan biaya yang timbul karena terjadi kerusakan di luar perkiraan yang menyebabkan mesin produksi terhenti waktu produksi sedang berjalan. Maka persamaan total cost minimum akan menjadi :

$$
\mathrm{Tc}(\mathrm{tp})=\frac{\mathrm{Cp} \times \mathrm{R}(\mathrm{tp})+\mathrm{Cf} \times(1-\mathrm{R}(\mathrm{tp}))}{\mathrm{tp} \times \mathrm{R}(\mathrm{tp})+\int_{0}^{\mathrm{t}} \mathrm{t} \times \mathrm{f}(\mathrm{t}) \mathrm{dt}}
$$

Tabel 7. Perhitungan total Preventif

\begin{tabular}{|c|l|c|c|c|c|c|}
\hline No & Komponen & $\begin{array}{c}\text { CM } \\
\text { (Rupiah) }\end{array}$ & $\begin{array}{c}\text { CF } \\
\text { (Rupiah) }\end{array}$ & TM (Jam) & TC & TP \\
\hline 1 & $\begin{array}{l}\text { Gear Box } \\
\text { Lifter }\end{array}$ & 4.023 .989 & 462.587 .455 & 106,0832268 & Rp3.825.000 & Rp288.594.239.596 \\
\hline 2 & Sprocket & 2.402 .749 & 475.282 .042 & 130,9544405 & Rp2.246.000 & Rp288.594.239.596 \\
\hline 3 & Scraper & 1.569 .970 & 457.045 .943 & 52,12530569 & Rp1.458.000 & Rp288.594.239.596 \\
\hline 4 & $\begin{array}{l}\text { Wiremesh } \\
\text { Belt }\end{array}$ & 5.140 .321 & 914.986 .152 & 125,263454 & Rp4.739.000 & Rp288.594.239.596 \\
\hline
\end{tabular}


Tabel 8. Akumulasi Biaya Sebelum dan sesudah

\begin{tabular}{|c|l|l|c|}
\hline \multirow{2}{*}{ No } & \multirow{2}{*}{ Komponen } & \multicolumn{2}{|c|}{ Total Biaya Penggantian Per Periode } \\
\cline { 3 - 4 } & & $\begin{array}{c}\text { Sebelum adanya } \\
\text { program } \\
\text { penggantian }\end{array}$ & $\begin{array}{c}\text { Setelah } \\
\text { adanya } \\
\text { program } \\
\text { penggantian }\end{array}$ \\
\hline 1 & Gear Box Lifter & Rp288.594.239.596 & Rp3.825.000 \\
\hline 2 & Sprocket & Rp288.594.239.596 & Rp2.246.000 \\
\hline 3 & Scraper & Rp288.594.239.596 & Rp1.458.000 \\
\hline 4 & Wiremesh Belt & Rp288.594.239.596 & Rp4.739.000 \\
\hline
\end{tabular}

\section{PENUTUP}

Adapun kesimpulan yang diperoleh dari hasil pembahasan adalah sebagai berikut:

1. Didapatkan data waktu antar kerusakan komponen dan data waktu perbaikan komponen. Berdasarkan hal tersebut jadwal pemeliharaan komponen kritis dapat dijadwalkan dengan interval perawatan sebagai berikut:

a. Gear Box Lifter dilakukan perawatan setiap 4 hari sekali

b. Sprocket dilakukan perawatan setiap 5 hari sekali

c. Scraper dilakukan perawatan setiap 2 hari sekali

d. Wiremesh Belt dilakukan perawatan setiap 5 hari sekali.

2. Didapatkan biaya perawatan (CM) untuk masing masing komponen kritis dengan perhitungan sebagai berikut:
a. Gear Box Lifter
Rp. 3.885.396
b. Scraper
Rp. 2.261 .868
c. Sprocket
Rp. 1.451 .564
d. Wiremesh Belt
Rp. 4.814 .772

Dari biaya perawatan diatas terlihat jauh lebih murah apabila dibandingkan dengan biaya perbaikan (breakdown maintenance) selisih biaya yang didapat pun cukup signifikan yaitu:

1. Gear Box Lifter = $\quad$ Rp 462.587.455

2. Scraper = Rp 475.282 .042

3. Sprocket = Rp 457.045 .943

4. Wiremesh Belt $\quad=$ Rp 914.986 .152

Jadi dengan perawatan preventif kerusakan yang ada dapat di maintenance secara baik dan dapat menghemat biaya kerusakan mesin sebesar Rp2.296.764.563.

\section{DAFTAR PUSTAKA}

Azis, M. T., Suprawhardana, M. S., \& Purwanto, T. P. (2010). Penerapan Metode Reliability Centered Maintenance (RCM) Berbasis Web Pada Sistem Pendingin Primer Di Reaktor Serba Guna Ga. Siwabessy. In Jurnal Forum Nuklir (Vol. 4, pp. 81-98).

Dhamayanti, D. S., Alhilman, J., \& Athari, N. (2016). Usulan Preventive Maintenance Pada Mesin KOMORI LS440 dengan Menggunakan Metode Reliability Centered Maintenance (RCM II) dan Risk Based Maintenance (RBM) di PT ABC. JRSI (Jurnal Rekayasa Sistem Dan Industri), 3(02), 31-37.

Prasetya, D., \& Ardhyani, I. W. (2019). Perencanaan Pemeliharaan Mesin Produksi Dengan Menggunakan Metode Reliability Centered Maintenance (RCM)(Studi Kasus: PT. S). JISO: Journal of Industrial and Systems Optimization, 1(1), 7-14. 